\title{
Formula Synthesis of Maximal Mechanical Torque on Volume for Cylindrical Magnetic Coupler
}

\author{
Baiba Ose-Zala (Doctoral student, Riga Technical University), Oskars Onzevs (Leading researcher, Turiba), \\ Vladislav Pugachov (Leading researcher, Institute of Physical Energetics)
}

\begin{abstract}
In this paper the influence of basic design parameters (proportionality coefficient $\beta$ and permanent magnets height $h$ ) on the mechanical torque for cylindrical magnetic coupler with rounded permanent magnets is researched. Such cylindrical magnetic couplers are often used in pumps and liquid mixers. At the beginning the design parameters and their relevance are explained. The mechanical torque is calculated applying the software QuickField. In the data analysis and for the coupler comparison the division of maximal mechanical torque on volume is taken as the main characteristic. Because of the planned optimization for the calculated variants there were synthesized few formulas, from which the most suitable were found (for all researched design parameters' ranges). The formulas are synthesized using a program, which is created by Oskars Onzevs. The program for the formula synthesis is based on regression models, and the basic principles of it are explained. All the calculations for experimental and formula data are made for magnetic coupler's design with one pole pair number $p$ that is equal to three.
\end{abstract}

Keywords - Data analysis, design optimization, finite element analysis, magnetic devices, permanent magnet machines.

\section{INTRODUCTION}

A magnetic coupler (MC) is a mechanism that is used to transfer the mechanical torque without a contact of the two main parts called half couplings. The torque is transferred using attraction and repulsion forces from permanent magnets placed on both half couplings [1]. For a cylindrical MC [2-5] there is an inner half coupling and an outer half coupling, where the first one is placed into the second one (outer half coupling). The bases of the half couplings are made of steel. Permanent magnets (PMs) are placed on the bases. Magnets most often are made of rear earth alloys such as neodymiumiron-boron (Nd-Fe-B) or samarium-cobalt (Sm-Co) [6]. Main design parameters for a cylindrical MC cross-section are given in Fig. 1.

Three more parameters are used as design parameters: the axial length $l$, the pole pair number $p$ and the proportionality coefficient $\beta$. The coefficient $\beta$ is expressed in (1):

$$
\beta=\frac{\alpha_{P M}}{\left(\alpha_{P M}+\alpha_{\delta}\right)},
$$

where $\alpha_{\mathrm{PM}}$ is the PM angle and $\alpha_{\delta}$ is the angle of air gap between two PMs placed next to each other (Fig. 2). These both angles together shape a pole pitch.

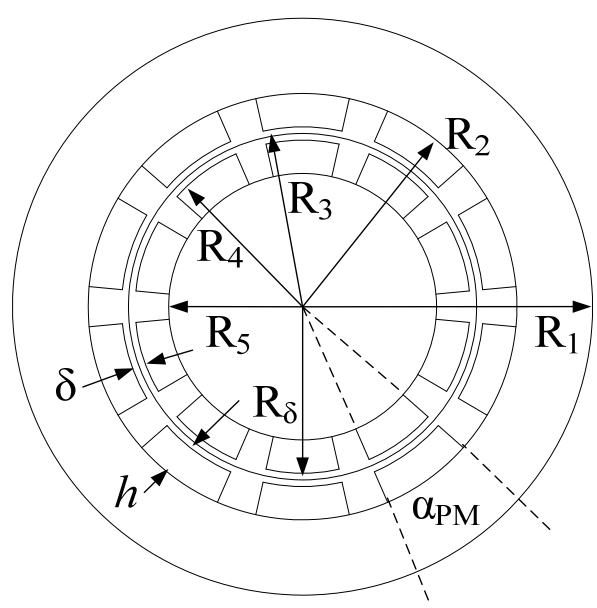

Fig. 1. Dimensions of cylindrical magnetic coupler in a cross-section. $\mathrm{R}_{1}-\mathrm{R}_{5}$ - radiuses; $\mathrm{R}_{\delta}$ - radius of air gap's middle circle; $\delta$ - air gap; $h$ - PMs height; $\alpha_{\mathrm{PM}}-$ angle of PM.

In this paper multivariate experiments' data is obtained [7], which is analysed and formulas are synthesized, as well as the most suitable formula from the synthesized is chosen (for given data). The most suitable formula is tested by design parameters values which are between variants made for formula synthesis.

Such variables have been analysed: permanent magnets' height $h$ (with values in millimetres $-6,6.5,7,7.5,8$ ), proportionality coefficient $\beta$ (with values $-0.7,0.8,0.9$ ) and axial length $l$ (with values in millimetres $-30,32,34,36,38$ ).

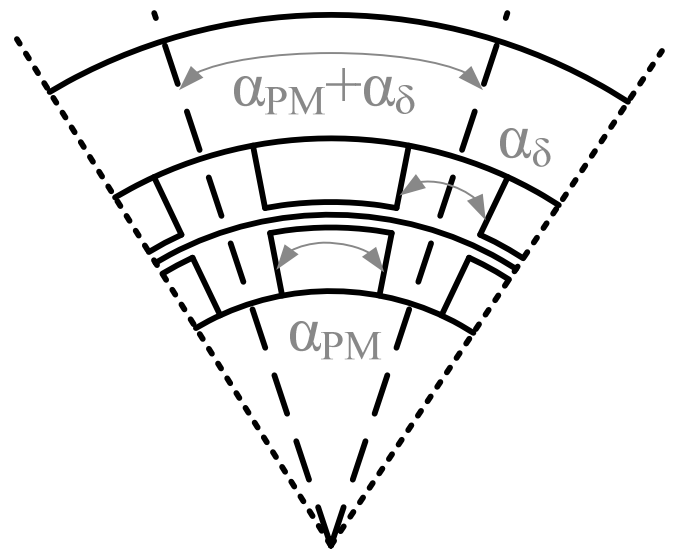

Fig. 2. The pole pitch, PM's angle and angle of the air gap. $\alpha_{\mathrm{PM}}-$ angle of PM; $\alpha_{\delta}$ - angle of air gap between two PMs placed next to each other. 
The goal function is the maximal mechanical torque on the volume. Earlier research [8] was made just taking the maximal mechanical torque of a MC as the goal function. As the height of yoke is calculated (2), every change of PMs height $h$, coefficient $\beta$ and pole pair number $p$ lead to design changes and thus the influence is not only direct but also indirect on the maximal mechanical torque. Thus it is more correctly to choose the maximal mechanical torque on volume for the goal function. But, as the calculation of volume includes the axial length $l$, it is important to make a calculation set just with two independent variables: permanent magnets' height $h$ and proportionality coefficient $\beta$.

$$
h_{\text {yoke }}=\frac{\pi \cdot R_{2} \cdot \beta}{p} \cdot \frac{B_{P M}}{B_{\text {steel }}}
$$

Other experiments showed that it is very complicated to obtain reliable synthesized formula for chosen interval of pole pair numbers: from 1 to 10 , by a step equal one. Accordingly in this paper just one value of pole pair number interval $(p=3)$ was chosen to be used for finding out if in this case it would be easier to synthesize reliable formula for the goal function for planned optimization.

The formulas were also synthesized by the same variables for two control parameters: maximal magnetic flux density in steel of inner half coupling $B_{\text {max }}$ in and maximal magnetic flux density in the yoke of outer half coupling $B_{\max \text { out }}$. Usually magnetic flux density maximal values are at the corners between the PM and the steel (Fig. 3).

And one more control parameter is the yoke of outer half coupling. It is necessary because in some cases it can be very small, e.g. $3.6 \mathrm{~mm}$, but in the further planned optimization program for the best choice it will be controlled, that the yoke cannot be less than $5 \mathrm{~mm}$ - the reputed value for electrical machine yoke by physical strength [9].

The maximal mechanical torque of the MCs is calculated using the software QuickField [10]. Some parameters must be defined for the calculations. The PM's are made of rear earth

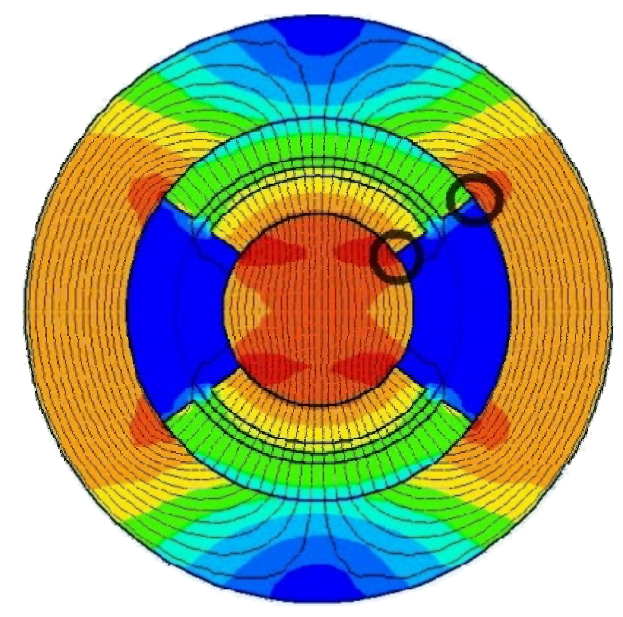

Fig. 3. The designed magnetic field for the magnetic coupler with $p=1$. Two black circles mark the places, where the magnetic flux density has its highest value. alloy neodymium-iron-boron and such parameters are used in the calculation:

- Residual magnetic flux density $\mathrm{B}_{\mathrm{r}}=1.3(\mathrm{~T})$;

- Coercive force $\mathrm{H}_{\mathrm{c}}=900(\mathrm{kA} / \mathrm{m})$;

- Relative permeability $\mu_{*}=1.15$.

\section{THE FORMULA SYNTHESIS}

The program for formula synthesis is written by Dr.sc.eng. Oskars Onzevs. The formula synthesis is based on the regression models [11]. This work was further developed for engineering calculations [12] and so the methodology is successfully used for synthesis in the electrical machine field $[13,14]$. The works of A. G. Ivakhnenko [15] determine the ideological criteria and the base of synthesis models.

The formula is synthesized as a sum of the elementary functions from the functions bank and mathematically it is expressed as (3):

$$
Y=A_{0}+\sum_{i=1}^{m-1} A_{i} g_{i}(X)
$$

where $X-$ is the vector of independent variables, $g_{i}(X)-$ elementary functions selected from the functions bank, $A_{i}-$ coefficients, which are obtained using the least squares method and $m$ - the amount of elementary functions taken from the functions bank.

The elementary functions in the bank are given in form (4):

$$
g_{i}(X)=\prod_{j=1}^{n} X_{j}^{a_{i j}}
$$

where $n$ is the number of independent variables and $a_{i j}-$ index for every independent variable $j$ in function $i$ (can also be zero and negative).

For the functions synthesis there are two stages. In the first one a sufficient number of elementary functions are selected and (3) type relevance is obtained, which is more complicated than necessary. Every next elementary function is selected so, that the residual $\Delta$ would be described in the best way (5):

$$
\Delta=A_{0}+\sum_{i=1}^{m-1} A_{i} g_{i}(X)-Y
$$

In the second stage the optimal relevance is found by complexity. It is done by cutting down the elementary functions one by one, which has the smallest influence on the inner criteria $\sigma$. Thus, in the elimination process, monotonous wane of inner criteria $\sigma$ is obtained (6):

$$
\sigma=\frac{1}{\sqrt{k-m+1}} \cdot \sqrt{\sum_{l=1}^{k}\left(A_{0}+\sum_{i=1}^{m-1} A_{i} g_{i}(X)-Y\right)^{2}},
$$

where $k$ - the number of experimental points.

To find the optimal complexity the outer criteria $\mathrm{C}(7)$ is calculated: 


$$
C=\left(1-\frac{\sigma}{\sigma_{0}}\right) \cdot 100 \%
$$

where $\quad \sigma_{0}=\sqrt{\frac{\sum_{l=1}^{k}\left(Y_{l}-\frac{1}{k} \sum_{i=1}^{k} Y_{i}\right)^{2}}{k-1}}$.

The breaking point in relevance (8), here named as elimination diagram, determines the model of optimal complexity.

$$
C=C(m)
$$

\section{SYNTHESIS FOR CHOSEN VARIABLES}

First the formula synthesis was made for three variables: proportionality coefficient $\beta$, axial length $l$ and PMs height $h$. When the relevance for $M_{\max } / V=f(\beta, l, h)$ is researched, then the axial length is not an independent variable. That also shows up in the synthesized variants, where there are used only independent variables: coefficient $\beta$ and PMs height $h$. Of the given five formulas one was chosen (9) to compare with the results given in QuickField for two variables.

$$
\begin{gathered}
M_{\max } / V=0.717+0.981 \beta+0.037 h- \\
-1.056 \beta^{2}-0.001 \beta \cdot h^{2}
\end{gathered}
$$

The graphs for this formula and experimental data at different PMs height $(6,6.5,7,7.5$ and $8 \mathrm{~mm})$ at coefficients $\beta$ $=0.7, \beta=0.8$ and $\beta=0.9$ are given in fig. 5 .

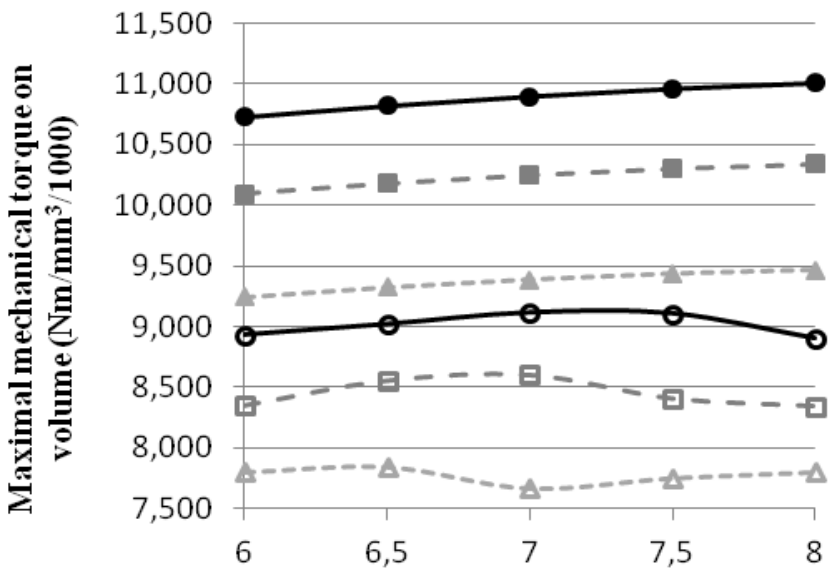

Permanent magnets' height (mm)

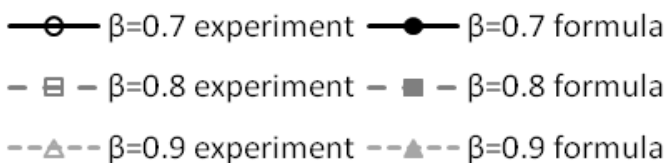

Fig. 5. The function $M_{\max }=f(h, \beta)$ for axial length $l=30 \mathrm{~mm}$.
The difference for all coefficient cases is high enough, when expressed in percentage - the middle deviation is $20 \%$. That is not acceptable. Further the results for synthesis by two independent variables are given.

From the six obtained formula variants one (10) was chosen to describe the main function - maximal mechanical torque on volume (Fig. 6). Experimental data is named "exper" and in some figures synthesized formula is named "formul" for short.

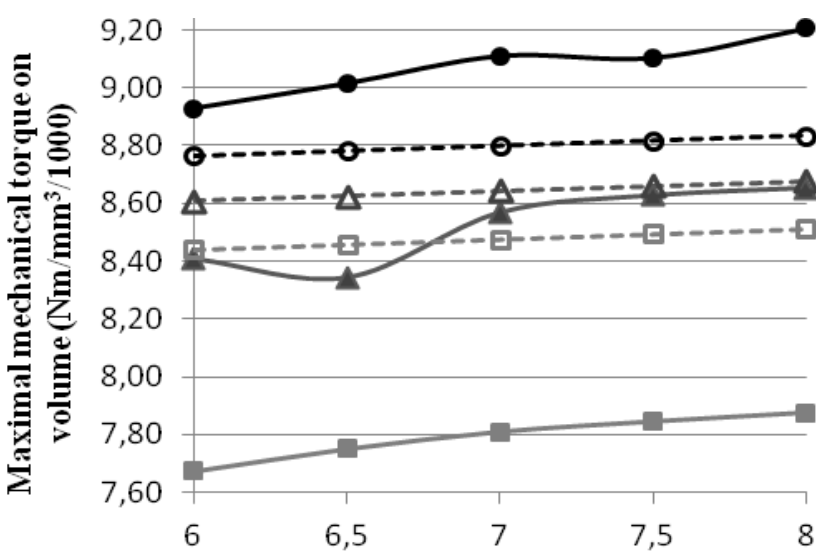

Permanent magnets' height (mm)

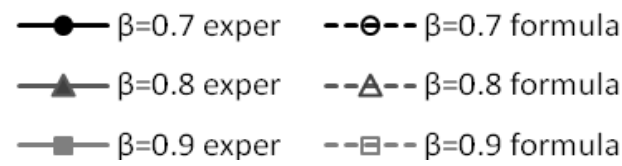

Fig. 6. The function $M_{\max }=f(h, \beta)(l=30 \mathrm{~mm})$.

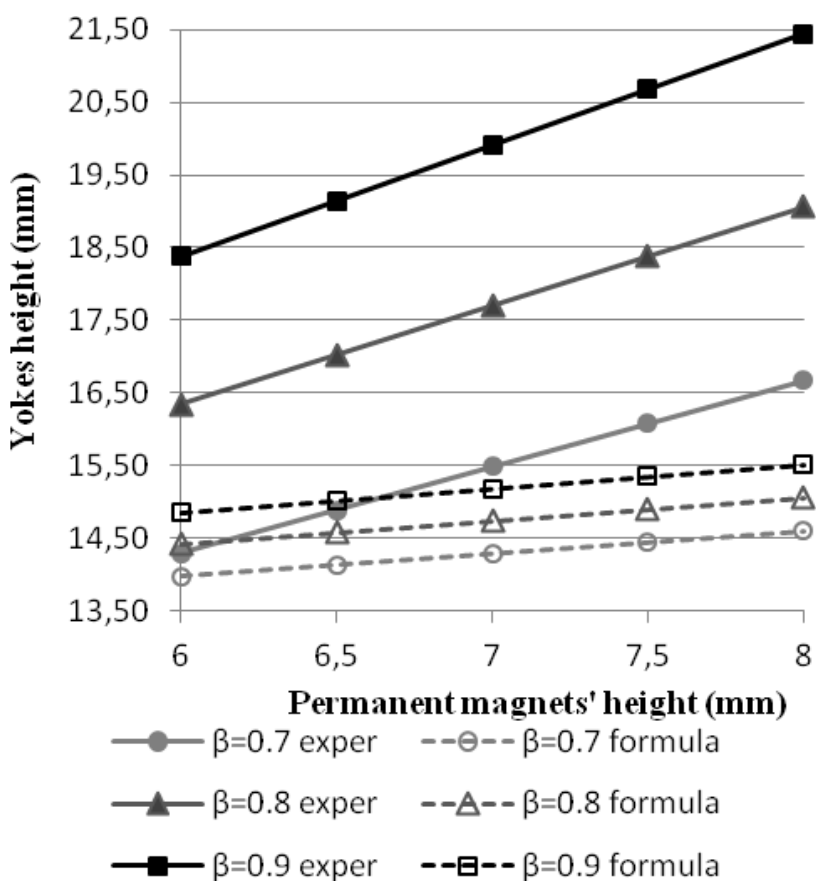

Fig. 7. The function $h_{\text {yoke }}=f(h, \beta)(l=30 \mathrm{~mm})$. 


$$
M_{\max } / V=10.256-1.976 \beta+0.036 h-0.225 \frac{1}{\beta}
$$

For a smaller proportionality coefficient $\beta(\beta=0.7)$ there is a higher value of maximal mechanical torque on volume (Fig. 6). Also higher permanent magnets give better values of $M_{\max } / V$. For this formula the deviation from experimental data is up to ten per cent, but the middle value of error is just four per cent, which is acceptable.

For the control parameter - yokes height $h_{\text {yoke }}-$ nine formula variants were obtained, from which one was chosen. The results are compared with the experimental data (Fig. 7).

If compare the experimental and the results obtained by formula then the graphs are proportional to each other, but the best conformity is only in the case when the proportionality coefficient is $\beta=0.7$.

For control parameters - maximal magnetic flux density in inner half coupling $B_{\max }$ in and in outer half coupling $B_{\text {max out }}-$ four formula variants were synthesized for each. In this case also were compared the function values in Excel and one formula was chosen for both parameters. The chosen formula result for $B_{\max }$ in is given for one case: proportionality coefficient $\beta=0.7$ and axial length $l=30 \mathrm{~mm}$ (Fig. 8). The formula results give a linear function though in reality it is much more complicated. It is accepted till further research.

The chosen formula for $B_{\max }$ out is given just for one proportionality coefficient $(\beta=0.8)$ and axial length $(l=32$ mm) case (Fig. 9).

There are given just a few samples out of all obtained data. For all magnetic flux density values the program is finding the best possible relation (with the aim to obtain useful formula) to independent variable PMs height $h$ (Fig. 8, Fig. 9) and to proportionality coefficient $\beta$. The maximal magnetic flux density (in inner and outer half couplings) value dependence on coefficient $\beta$ is given in fig. 10.

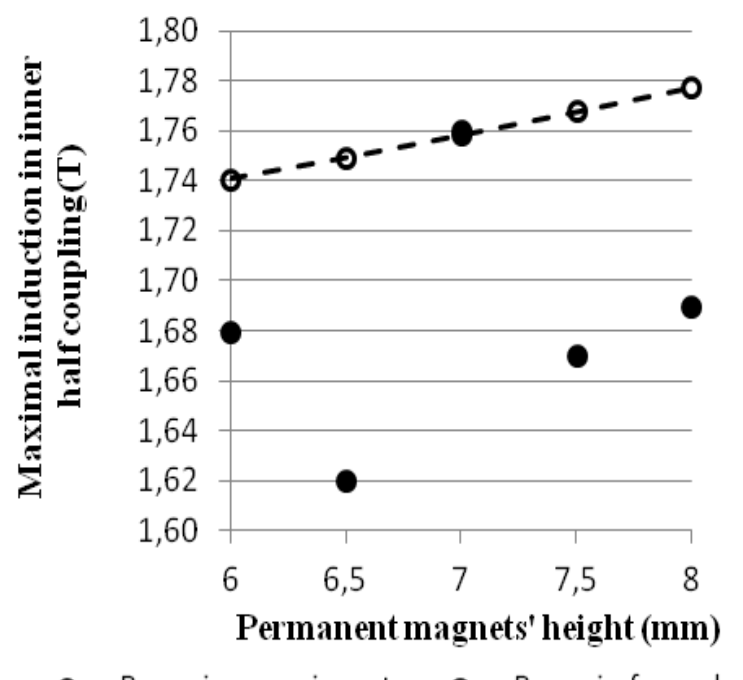

Fig. 8 . The function $B_{\max }$ in $=f(h),(\beta=0.7, l=30 \mathrm{~mm})$.
In this case the functions for maximal magnetic flux density are simpler than in reality, where the dependence is more complicated and is not linear, on the contrary as for the yokes height (Fig. 7).

\section{Testing The ChOSEn Formulas}

Thirteen additional experiments were made to check, how the formulas behave for design variants, which are between the parameters values used for formula synthesis.

The additional variants are made in such principle:

1) The proportionality coefficients $\beta$ are constant and PM height $h$ is changed;

2) The PM heights $h$ are constant as used for synthesis but proportionality coefficients $\beta$ are varied;

$3)$ Both variables $(h, \beta)$ were varied with values, which were not used in formula synthesis.

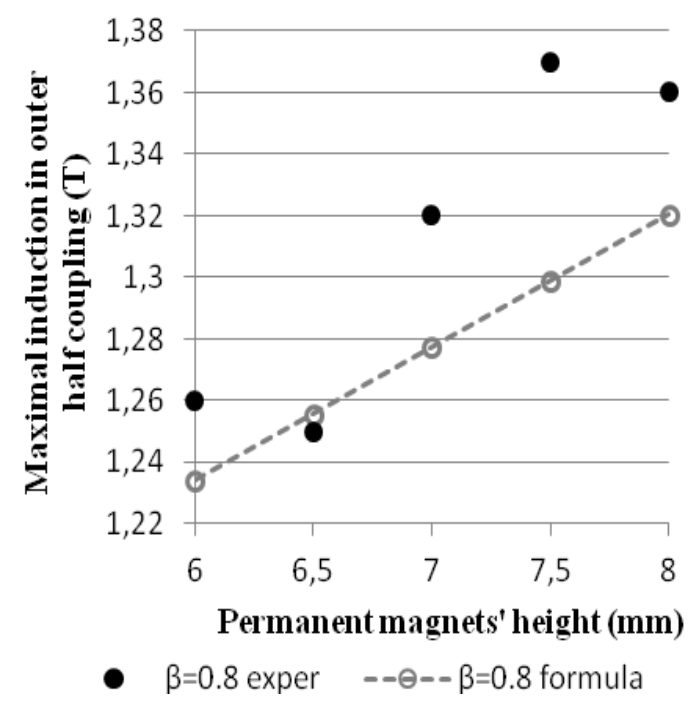

Fig. 9. The function $B_{\max \text { out }}=f(h),(\beta=0.8, l=32 \mathrm{~mm})$.

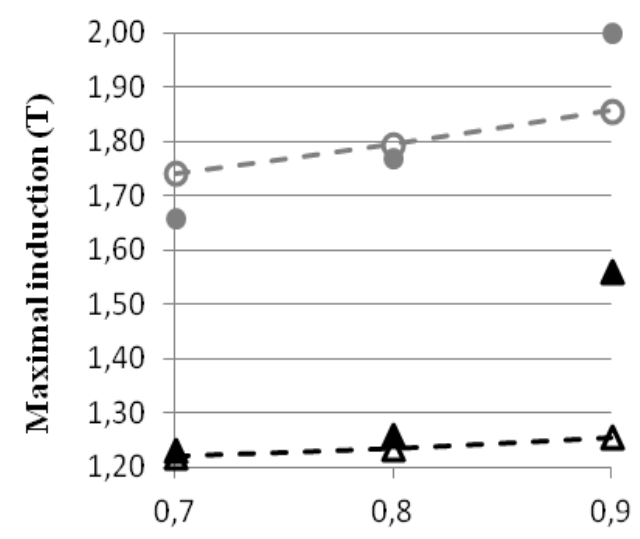

Proportionality coefficient

- Bin exper $-\ominus-$ Bin formula

$\Delta$ Bout exper $-\boldsymbol{\Delta}$ - Bout formula

Fig. 10. The function $B_{\text {max in }}=f(\beta), B_{\text {max out }}=f(\beta),(h=6 \mathrm{~mm}, l=34 \mathrm{~mm})$. 


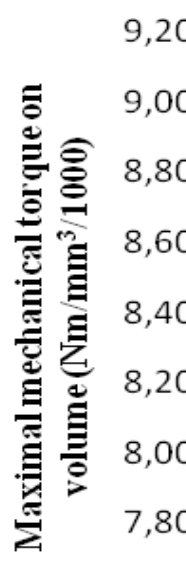

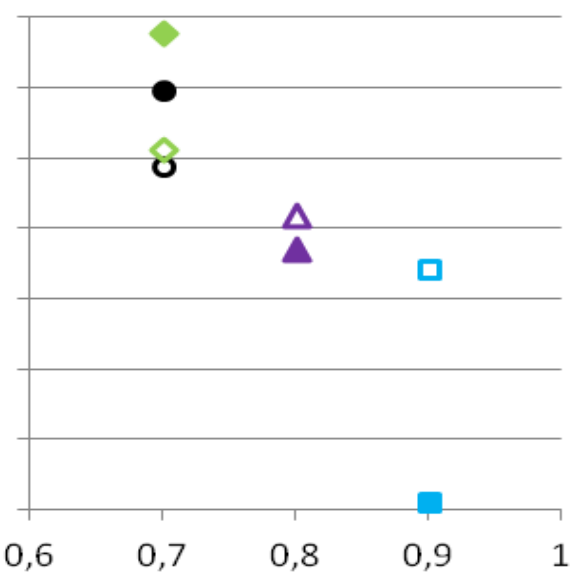

Proportionality coefficient

$\mathrm{h}=6,3 \mathrm{~mm}$ (exper)

$\mathrm{h}=7,2 \mathrm{~mm}$ (exper)

$\mathrm{O}=6,3 \mathrm{~mm}$ (formul)

$\square \mathrm{h}=7,2 \mathrm{~mm}$ (formul)

$\Delta \mathrm{h}=6,8 \mathrm{~mm}$ (exper)

$\mathrm{h}=7,7 \mathrm{~mm}$ (exper)

$\Delta \mathrm{h}=6,8 \mathrm{~mm}$ (formul)

$\diamond \mathrm{h}=7,7 \mathrm{~mm}$ (formul)

Fig. 11. Test variants for varied PM height $h(l=30 \mathrm{~mm})$.

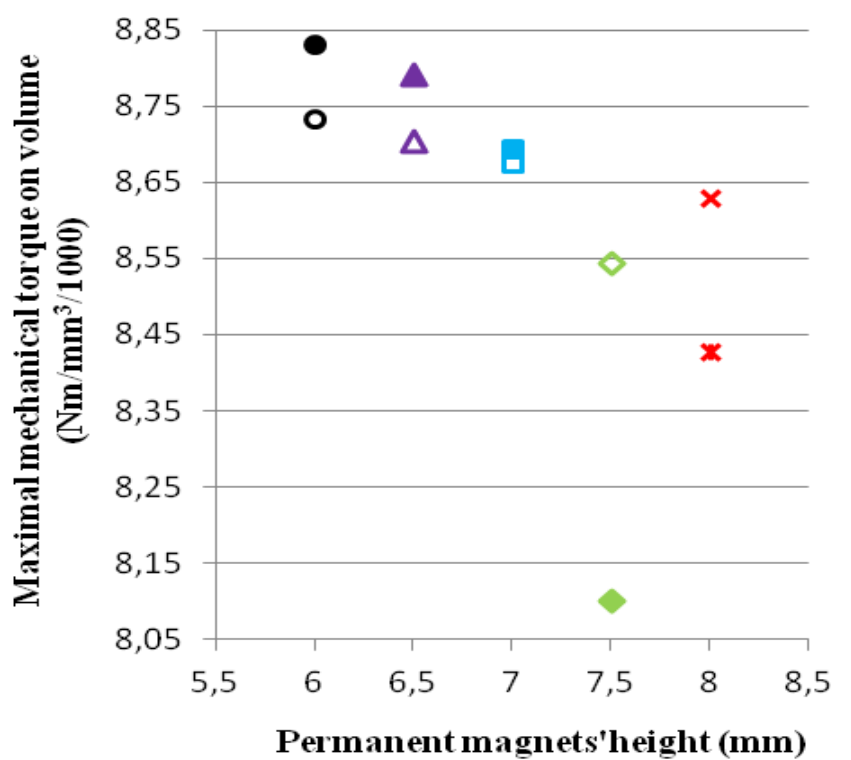

TABLE I

MAXIMAL MECHANICAL TORQUE ON VOLUME FOR DIFFERENT VARIABLES

\begin{tabular}{|c|c|c|c|c|c|}
\hline \multirow{2}{*}{ 营 } & \multirow{2}{*}{$\begin{array}{c}\text { Proportionality } \\
\text { coefficient } \beta\end{array}$} & \multirow{2}{*}{$\begin{array}{c}\text { PM's } \\
\text { height } h \\
\text { (mm) }\end{array}$} & \multicolumn{2}{|c|}{$\begin{array}{c}M_{\max } / V \\
\left(\mathrm{Nm} / \mathrm{mm}^{3} / \mathbf{1 0 0 0}\right)\end{array}$} & \multirow{2}{*}{$\begin{array}{c}\text { Offset } \\
(\%)\end{array}$} \\
\hline & & & $\begin{array}{l}\text { Experi- } \\
\text { mental }\end{array}$ & Formula & \\
\hline 10. & 0.73 & 6.4 & 8.871 & 8.733 & 1.6 \\
\hline 11. & 0.77 & 6.7 & 8.722 & 8.680 & 0.5 \\
\hline 12. & 0.82 & 7.3 & 8.468 & 8.621 & 1.8 \\
\hline 13. & 0.86 & 7.6 & 8.176 & 8.565 & 4.8 \\
\hline
\end{tabular}

The previous analysis showed that for proportionality coefficient $\beta=0.9$ the formula gives more diverse values of goal function comparing to experimental data. The same can be seen in Fig. 11, where by standard coefficient $\beta=0.9$ for special PM height $(h=7.2 \mathrm{~mm})$ is the largest offset. The same situation is seen (Fig. 12), when the coefficient $\beta$ is changed in interval from 0.8 to $0.9(\beta=0.83, \beta=0.87)$, especially, when the $\beta$ value is closer to 0.9 .

For test variants, where variables are varied (coefficient $\beta$ and PM height $h$ ), the experimental data and the results from formula are given in Table I.

For the main function the results of first and second test variants are given accordingly in Fig. 11 and Fig. 12. The filled markers are for experimental data ("exper") and the markers without fill are for formula given results ("formul").

The offsets of formula results comparing to experimental data are lower than five per cent, such obtained results are acceptable and thus this formula can be used. Though for the proportionality coefficient $\beta=0.9$ there must be made additional research to decide, if this is not an exceptional case and another formula should be used.

For the control parameter - yoke's height $h_{\text {yoke }}$ - additional variants with the results are given in Table II.

TABLE II

YOKE'S HEIGHT FOR DIFFERENT VARIABLES

\begin{tabular}{|c|c|c|c|c|c|}
\hline \multirow{2}{*}{ 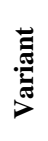 } & \multirow{2}{*}{$\begin{array}{c}\text { Proportionality } \\
\text { coefficient } \boldsymbol{\beta}\end{array}$} & \multirow{2}{*}{$\begin{array}{c}\text { PM's } \\
\text { height } h \\
\text { (mm) }\end{array}$} & \multicolumn{2}{|c|}{$h_{\text {yoke }}(\mathrm{mm})$} & \multirow{2}{*}{$\begin{array}{c}\text { Offset } \\
(\%)\end{array}$} \\
\hline & & & $\begin{array}{l}\text { Experi- } \\
\text { mental }\end{array}$ & Formula & \\
\hline 1. & 0.7 & 6.3 & 14.65 & 14.20 & 3.1 \\
\hline 2. & 0.8 & 6.8 & 17.43 & 14.81 & 15.0 \\
\hline 3. & 0.9 & 7.2 & 20.22 & 15.39 & 23.9 \\
\hline 4. & 0.7 & 7.7 & 16.32 & 14.64 & 10.3 \\
\hline 5. & 0.72 & 6 & 14.70 & 14.20 & 3.4 \\
\hline 6 & 0.75 & 6.5 & 15.95 & 14.49 & 9.2 \\
\hline 7. & 0.78 & 7 & 17.26 & 14.78 & 14.3 \\
\hline 8. & 0.87 & 7.5 & 19.99 & 15.35 & 23.2 \\
\hline 9. & 0.83 & 8 & 19.77 & 15.33 & 22.4 \\
\hline 10. & 0.73 & 6.4 & 15.40 & 14.37 & 6.7 \\
\hline 11. & 0.77 & 6.7 & 16.64 & 14.64 & 12.0 \\
\hline 12. & 0.82 & 7.3 & 18.56 & 15.06 & 18.8 \\
\hline 13. & 0.86 & 7.6 & 19.90 & 15.34 & 22.9 \\
\hline
\end{tabular}


TABLE III

MAXIMAL FluX DENSITY FOR DifFERENT VARIABLES

\begin{tabular}{|c|c|c|c|c|}
\hline \multirow{2}{*}{ 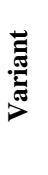 } & \multicolumn{2}{|c|}{$B_{\text {max in }}(\mathrm{T})$} & \multicolumn{2}{|c|}{$B_{\text {max out }}(\mathrm{T})$} \\
\hline & $\begin{array}{l}\text { experiment } \\
\text { al }\end{array}$ & formula & $\begin{array}{l}\text { experiment } \\
\text { al }\end{array}$ & formula \\
\hline 1. & 1.54 & 1.75 & 1.29 & 1.23 \\
\hline 2. & 1.70 & 1.81 & 1.22 & 1.27 \\
\hline 3. & 1.94 & 1.88 & 1.43 & 1.31 \\
\hline 4. & 1.65 & 1.77 & 1.24 & 1.29 \\
\hline 5. & 1.61 & 1.75 & 1.26 & 1.22 \\
\hline 6 & 1.64 & 1.78 & 1.31 & 1.25 \\
\hline 7. & 1.78 & 1.80 & 1.30 & 1.27 \\
\hline 8. & 1.96 & 1.87 & 1.49 & 1.31 \\
\hline 9. & 1.94 & 1.85 & 1.45 & 1.33 \\
\hline 10. & 1.72 & 1.76 & 1.26 & 1.24 \\
\hline 11. & 1.72 & 1.79 & 1.27 & 1.26 \\
\hline 12. & 1.90 & 1.83 & 1.42 & 1.29 \\
\hline 13. & 1.87 & 1.86 & 1.45 & 1.31 \\
\hline
\end{tabular}

For four additional variants the offset is under $10 \%$, so the obtained results are not acceptable and further research for yoke's height as control parameter should be made.

For other two control parameters (maximal magnetic flux density in inner and outer half coupling) the results from additional variants are given in Table III. (The values of coefficient $\beta$ and PM height $h$ are not showed because they are the same as in Table II).

For both maximal magnetic flux densities one additional variant existed where the offset is more than $10 \%$. For maximal magnetic flux density in inner half coupling the average offset is $5.3 \%$, similarly for maximal magnetic flux density in outer half coupling - 5.6\%. The results are acceptable, but during optimization such situations must be avoided (bolded variant for $B_{\max }$ in, Table III), when the formula gives higher maximal magnetic flux density than in the experiment, when the controlled value is higher than the necessary. In this case in reality the maximal magnetic flux density would be $B_{\max \text { in }}=1.70 \mathrm{~T}$, but in optimization the formula result $B_{\max \text { in }}=1.81 \mathrm{~T}$ would be used. As the control value for $B_{\max }$ in is 1.80 , then, even if it was for the $M_{\max } / V$ optimum, this optimum would be abandoned, because $1.81>$ $1.80(\mathrm{~T})$.

\section{V.CONCLUSIONS}

From the obtained data it can be concluded, that the highest value of goal function (maximal mechanical torque on volume) is at coefficient equal to $\beta=0.7$, at higher permanent magnets $(h=8 \mathrm{~mm})$ and, of course, at the longest axial length l. These three variables are independent for researching the value of maximal torque, but, when the function for $M_{\max } / V$ is researched, the axial length $l$ is not independent, because it is included in the volume calculation.

The program recognises a situation, that axial length is not an independent variable, and synthesizes the formulas only with two independent variables.

Six formulas were synthesized during the research of the function $M_{\max }=f(h, \beta)$ (when two independent variables), from which the one that describes the relevance $M_{\max }=f(h, \beta)$ very well was chosen.

Formulas should be researched and synthesized for all control parameters that fit better the experimental results, especially for the yoke's height. For maximal magnetic flux densities in inner and outer half couplings the results are mathematically acceptable. It is important to avoid situations, when the formula gives higher value than it is taken experimentally, especially when the values are: $B_{\max \text { in }} \leq 1.8 \mathrm{~T}$, $B_{\text {max out }} \leq 1.6 \mathrm{~T}$.

The research and formula synthesis must be continued for all pole pair numbers ( $p$ from 1 to 10 ), because in this work only the case when pole pair number is equal 3 was researched.

\section{REFERENCES}

[1] B. Ose, V. Pugachov, S. Orlova, "The influence of PM's construction parameters in magnetic coupler on its mechanical torque," Proceedings of the 6th International Conference on Electrical and Control Technologies (ECT 2011), Lithuania, Kaunas, 4-6 May, 2011, pp. 226230.

[2] Muzalevsky V. I., Iskurihin I.B. Magnitnaya mufta. RU (11) 2130137 (13) C1. 10.05.1999.

[3] R. M. Hornreich, S. Shtriman. Optimal Design of Synchronous Torque Couplers. IEEE Transaction on Magnetics, Vol. MAG-14, No. 5 . September, 1978.

[4] H. Kojima, K. Nagaya. Nonlinear Torsianal Vibration of a Rotating Shaft System with a Magnet Coupling. Bulletin of JSME, Vol. 27, No. 228. June, 1984.

[5] C. J. Fellows. Permanent Magnet Couplings. CME,June, 1979. Pp. 7984.

[6] Ose, B.; Pugachov, V.; Orlova, S.; Vanags, J., "The influence of permanent magnets' width and number on the mechanical torque of a magnetic coupler with rectangular permanent magnets," Industrial Electronics (ISIE), 2011 IEEE International Symposium on , vol., no., pp.761,765, 27-30 June 2011

[7] J. F. Hair jr., W. C. Black, B. J. Babin and R. E. Anderson, Multivariate data analysis, 7th ed. New Jersey: Prentice Hall, 2010. 762 p.

[8] Ose, B. \& Pugachov, V. (2011). The Influence of Pole Pair Number and Magnets' Width on Mechanical Torque of Magnetic Coupler with Rounded Permanent Magnets. Scientific Journal of Riga Technical University. Power and Electrical Engineering, 28(-1), pp. 63-66. Retrieved 12 Aug. 2013, from doi:10.2478/v10144-011-0011-0

[9] I. M. Postnikov, Projektirovanije elektricheskih mashin. Kiev: Gosudarstvennoje izdatelstvo tehnicheskoj literaturi USSR (RU), 1952. $736 \mathrm{~s}$.

[10] QuickField User' Guide version 5.8. [Online]. Available: http://www.quickfield.com [Accessed May 2, 2012].

[11] V. O. Eglais, Approksimacija tablishnih dannih mnogomernim uravnenijem regressiji: Voprosi dinamiki i prochnosti. Riga, 1981. Vip. 39, s. 120.-125 (RU).

[12] A. Janushevskis, E. Lavendelis and O.Onzevs, "Method for optimization of random vibrations of non-linear mechanical system". Proceedings of IUTAM / IFToMM Symposium on Synthesis of Nonlinear Dynamical Systems, Vol.73, 2000. pp. 159-168. Dordrecht / Boston / London: Kluwer Publishers. 
[13] O. Onzevs, I. Tihenko, N. Povetkina and J. Dirba, "Electronic Motors: Optimization Problems," Latvian Journal of Physics and Technical Sciences, No. 3, pp. 71-76, 1997.

[14] O. Onzevs, J. Dirba and I. Tihenko, "Methodology for Visual Estimation of Electronic Motors," Latvian Journal of Physics and Technical Sciences, No. 3, pp. 32-37, 1998.

[15] H. R .Madala and A. G. Ivakhnenko, Inductive learning algorithms for complex systems modeling. London, Tokyo: CRC Press, 1994.

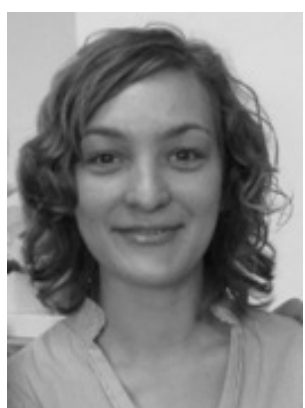

Baiba Ose-Zala is a scientific assistant in Institute of Physical Energetics, in Riga. Born 1987. Defended Mag.sc.eng. in 2010, in Riga Technical University, Department of Power and Electrical Engineering.

Worked in LATVENERGO, BELSS. Now works in Institute of Physical Energetics (Latvia, Riga). Fields of scientific interests: machines with permanent magnets, other permanent magnet applications for electro techniques, permanent magnets, electric cars, electrical machines.

Aizkraukles street 21, Riga, LV-1006, Latvia. Phone: +371 29177492, e-mail: baiba.ose@gmail.com.

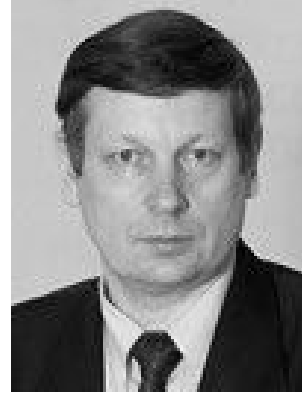

Oskars Onzevs is a leading researcher in Business Technology Institute at School of Business Administration Turiba and assistant professor in School of Business Administration Turiba, dr. sc. ing., born 1955.

Fields of scientific interests: identification, modelling and optimization of complex systems, application of IT in entrepreneurship, economic and financial models and their applications.

$\mathrm{He}$ is an author and co-author of more than 50 publications, including 3 patents.

School of Business Administration Turiba. +37129251009, e-mail: onzevs@turiba.lv.

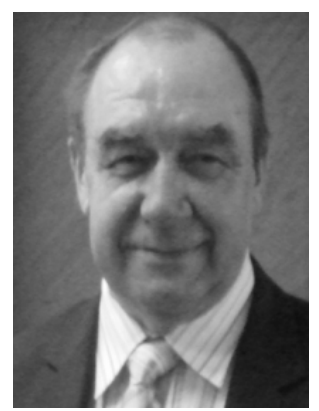

Vladislav Pugachov is Head of Laboratory in Institute of Physical Energetics, dr.habil.sc.eng. Born 1940.

Works in the Institute of Phyical Ebnergetics, Riga. Fields of interests: brushless electrical machines and drives, machines with permanent magnets, permanent magnets for electro technical appliance and medical devices, plastic bonded magnets technology and making.

$\mathrm{He}$ is an author and co-author of more than 150 publications, including 4 scientific books and 50 patents and inventors certificates.

Aizkraukles street 21, Riga, LV-1006, Latvia. Phone: +371 7558684, fax: +371 07550839, e-mail: magneton@edi.lv. 